\title{
"VAMOS SABOTAR AS ENGRENAGENS DESSE SISTEMA": GÊNERO E SEXUALIDADE NO PROGRAMA AMOR \& SEXO \\ “LET'S SABOTAGE THE GEARS OF THIS SYSTEM": GENDER AND SEXUALITY IN THE AMOR \& SEXO TV SHOW
}

Diego Gouveia Moreira*

Daniela Nery Bracchi**

Cristina Teixeira Vieira de Melo**

\section{RESUMO:}

A reivindicação por políticas identitárias tem ganhado cada vez mais espaço na agenda social. Para não ficar de fora desse debate, os meios de comunicação investem em produções que focalizam essas temáticas. O programa "Amor \& Sexo", da Rede Globo de Televisão, ao tratar de sexualidade, guia-se por questões que dizem respeito à identidade de gênero e à diversidade sexual. Sendo assim, o objetivo deste artigo é analisar as estratégias discursivas utilizadas pelo programa para abordar gênero e sexualidade. Por meio da análise feita, foi possível identificar que, no geral, a produção contribui para uma ampliação nos modos em que os temas identidade de gênero e práticas sexuais são discutidos no entretenimento televisivo. No entanto, nota-se um reducionismo ao abordar questões como a definição de sexo biológico e os papéis sociais de homens e mulheres.

\section{PALAVRAS-CHAVE:}

Amor \& Sexo, gênero, sexualidade.

\section{ABSTRACT:}

The demand for identity policies has gained more and more space on the social agenda. In order not to be left out of this debate, the media invest in productions that focus on these themes. The "Amor \& Sexo" program, from Rede Globo de Televisão, when

\footnotetext{
* $\quad$ Professor adjunto do Núcleo de Design e Comunicação do Centro Acadêmico do Agreste da Universidade Federal de Pernambuco (UFPE). Doutor em Comunicação pela UFPE. diego.moreira@ufpe.br

** Professora do Núcleo de Design e Comunicação do Centro Acadêmico do Agreste da Universidade Federal de Pernambuco. Doutora em Semiótica e Linguística Geral pela USP. daniela.bracchi@ufpe.br

*** Professora do Departamento de Comunicação e do Programa de Pós-graduação em Comunicação da Universidade Federal de Pernambuco. Doutora em Linguística pela Universidade Estadual de Campinas (Unicamp). cristina. melo@ufpe.br
} 
dealing with sexuality, addresses issues related to gender identity and sexual diversity. The purpose of this article is to analyze the discursive strategies used by the program to address gender and sexuality. Through the analysis made, it was possible to identify that, in general, the production contributes to an expansion in the ways in which gender identity and sexual practices are discussed in television entertainment. However, there is a reductionism in addressing issues such as the definition of biological sex and the social roles of men and women

\section{KEYWORDS:}

Amor \& Sexo, gender, sexuality.

\section{INTRODUÇÃO}

Dia 26 de janeiro de 2017, no lançamento da décima temporada de "Amor \& Sexo", programa da TV Globo, a apresentadora Fernanda Lima se propôs a falar sobre feminismo. Suas palavras na abertura do programa foram: "Para começar, a gente acredita na igualdade entre homens e mulheres. Para quem não sabe, isso é feminismo. Simples assim". (LIMA, 2017a) Esse foi o pontapé para uma edição que relembrou a famosa queima de sutiãs das mulheres na década de 1960. Convidadas e integrantes jogavam seus sutiãs em um barril com fumaça e diziam frases feministas de protesto.

Pelo prazer de ser uma mulher homossexual. A minha roupa curta não é um convite para você. Mulher preta não é só sexo. Eu não preciso vestir 36. Eu não mereço ser estuprada. Drags, trans e travestis, direito é bom. Não à LGBTfobia. (Amor \& Sexo, 2017)

Nos últimos anos, as demandas das mulheres e da população de Lésbicas, Gays, Bi, Trans, Queer/Questionando, Intersexo, Assexuais/Arromânticas/Agênero, Pan/Poli, e mais (LGBTQIAP+) têm ocupado não apenas as ruas, com o avanço dos movimentos sociais, mas também espaço nos meios de comunicação, sejam eles massivos ou alternativos. De modo que as reivindicações por políticas identitárias se somam à luta por políticas sociais.

De olho nesses movimentos, a TV Globo busca incorporar discussões associadas às reivindicações desses grupos em sua grade de programação. Foi assim com a questão da periferia e os programas "Central da Periferia", “Cidade dos Homens" e "Antônia”. Agora, sobressaem-se discursos sobre gênero e sexualidade. 
Um dos programas da emissora mais expressivo no tratamento dessas questões foi “Amor \& Sexo”, que, de 2009 a 2018, se propôs a tratar de maneira divertida o tema do sexo e dos relacionamentos. Ao longo dos dez anos de existência, foi só a partir de 2016 que a produção se apresentou para o público como um espaço de discussão política em torno do gênero e da sexualidade. Isso se percebe, porque, a partir de então, as edições passaram a ser temáticas, abordando essas questões sob um viés de direitos.

Com um título que faz alusão aos aspectos afetivos e sentimentais dos relacionamentos amorosos, incluindo as questões culturais e pretensamente naturais do sexo, o programa se diferenciou de outros exibidos na televisão por apresentar duas perspectivas não usuais sobre o tema. A primeira foi falar de amor e sexo de maneira lúdica, por meio de um programa de auditório. A segunda foi discutir essas temáticas com não especialistas, fugindo do tradicional modelo de perguntas do público leigo a algum perito no assunto, como se vê por exemplo no programa “Altas Horas", da mesma emissora, no qual a sexóloga Laura Muller tira dúvidas das pessoas.

O objetivo deste artigo é analisar as estratégias discursivas utilizadas pelo programa para abordar gênero e sexualidade, analisando seus discursos não-verbais e verbais. Para tanto, acompanhou-se o programa “Amor \& Sexo” por meio de registros descritivos-interpretativos em diários de observação. Nossa hipótese é a de que "Amor \& Sexo" constitui um espaço de entretenimento em que a TV Globo abre a possibilidade de discussão de temáticas políticas. Como fundamentação teórica, foram utilizados os estudos de gênero e sexualidade a partir de Judith Butler (1999; 2016), Paul B. Preciado (2014a; 2014b; 2014c) e Michel Foucault (2009).

\section{"AMOR \& SEXO” E OS DISCURSOS NÃO-VERBAIS LIGADOS A GÊNERO E SEXUALIDADE}

Ribeiro (2010, p. 19) afirma que, em geral, a mídia costumava abordar a sexualidade com deboche, discriminação e caricaturização. Com o avanço das pautas de reivindicação dos movimentos feministas e LGBTQIAP+, e suas consequentes conquistas de direitos, a programação televisiva precisou se adaptar.

Se, antes, havia um “Zorra Total” (1999-2015) com personagens gays estereotipados e com mulheres, negros e indígenas em situações constrangedoras, atualmente observa-se um movimento em abordar com humor, mas com discurso político marcado, temas 
importantes para questões identitárias desses grupos sociais. As telenovelas passaram a contar com personagens que contribuem para ações socioeducativas em torno das questões de gênero e sexualidade.

No terreno dos programas de auditório, “Amor \& Sexo”, comandado por Fernanda Lima, despontou como o lugar para discutir sobre gênero e sexualidade. Para colaborar com a discussão, contava com a presença de convidados, plateia e banda. Foram exibidas 103 edições ao longo de 11 temporadas, sendo que em todas há um objetivo claro de entreter falando sobre sexo, gênero e relacionamento.

Do ano de estreia até 2014, o programa teve a pretensão de conversar sobre sexo com toda a família, no sofá da sala. Portanto, essas primeiras temporadas eram compostas por reportagens feitas nas ruas, cujas temáticas eram discutidas no estúdio com a participação da plateia. A produção, nessa época, já contava com auditório, banda e convidados. Em 2015, não foi exibido, mas voltou em 2016 a pedido, segundo a emissora, do público. Já em 2016, mais precisamente nas edições de 2017 e 2018, o programa ganhou um discurso político mais engajado, falando sobre feminismo, machismo, homofobia, LGBTfobia e identidade de gênero. Essa é a principal diferença das últimas temporadas para as primeiras: o discurso político engajado. A ideia é desfazer preconceitos e ressignificar questões ligadas ao gênero e a sexualidade.

Para este artigo, descartamos os episódios que tratam de assuntos gerais, como felicidade, brasilidade e educação, de forma que foram observados episódios diretamente ligados a questões de gênero. Focalizamos as temporadas mais recentes, uma vez que, como já anunciado, elas representam o período de posicionamento político mais ativo do programa, falando sobre gênero e sexualidade sob uma perspectiva de desconstrução de padrões, ideias e valores acerca das temáticas. Assim, selecionamos os episódios de 26 de janeiro de 2017 (Mulher), 2 de março de 2017 (Orgulho LGBT), 23 de outubro de 2018 (Família) e 6 de novembro de 2018 (Estereótipos femininos e machismo) para análise.

“Amor \& Sexo" atende ao que se espera de um programa de auditório, ou seja, enquanto forma televisiva, não subverte o gênero ao qual faz parte. 0 início de cada edição se dá, normalmente, com uma apresentação musical coreografada na qual a apresentadora Fernanda Lima canta, ou apenas dança, com bailarinos. A música tem um espaço privilegiado no programa, que conta com uma média de três ou quatro apresentações 
por edição. As canções são, em sua quase totalidade, brasileiras. O programa articula a temática em discussão com canções nacionais que remetem ao assunto do dia. Uma vez que o conteúdo das músicas é importante para o discurso que se quer construir, a escassez de músicas estrangeiras se justifica, pois veicular canções em outras línguas pode ser uma barreira para a compreensão do grande público. Há, no entanto, edições como a da estreia da temporada de 2017, em que são cantadas e coreografadas músicas com cunho político, como “Run The World (Girls)”, numa tradução livre "Quem manda no mundo (Garotas)", da cantora Beyoncé, em que a emancipação feminina é pautada.

Após a abertura musical do programa, Fernanda Lima apresenta o tema da edição e convida o júri a tomar assento. Ao longo das edições, o júri foi mudando de composição, mas normalmente era composto por cinco pessoas. Participaram como jurados das exibições aqui analisadas, que seriam as de 2017 e 2018, a filósofa feminista Djamila Ribeiro, o estilista Dudu Bertholini, a psicanalista Regina Navarro Lins, o comediante Eduardo Sterblitch, o ator José Loreto, a atriz Mariana Santos, o apresentador Otaviano Costa e a jornalista Milly Lacombe. Depois da apresentação do júri, o programa anuncia os convidados e convoca a plateia para, a partir de jogos, ou quadros de entrevista, participarem da edição. É interessante observar que Djamila Ribeiro atuou como consultora do programa, demonstrando o esforço da produção em abordar os temas de uma forma mais adequada. O programa contava também com a consultoria permanente de Carmita Abdo, psiquiatra, sexóloga e professora da Universidade de São Paulo.

Para compreender melhor os enunciados de “Amor \& Sexo”, nos deteremos, inicialmente, aos aspectos visuais do programa, em que consideramos os elementos espaciais da exibição (circular, característico da arena, onde o centro é palco das apresentações de músicas e quadros de brincadeiras), as roupas (dos bailarinos, da apresentadora, dos jurados e dos participantes), as maquiagens e os acessórios exibidos.

Uma das principais figuras que encarna, visualmente, os valores do programa é a apresentadora Fernanda Lima. Sua estreia nos programas televisivos se dá em 1999, ao apresentar o “Mochilão MTV”, e, no ano seguinte até 2003, na mesma emissora, exibe o "Fica Comigo", programa em que jovens buscam um par amoroso. Percebemos, portanto, que o nome escolhido para ser a cara de “Amor \& Sexo” tem uma trajetória ligada ao público jovem e a programas que tratam de relacionamentos amorosos. 
Em “Amor \& Sexo”, a apresentadora tem o papel de narradora dos temas e dos quadros do programa. Na construção de sua persona, chama a atenção o modo como a atriz se veste, pois a apresentadora investe em roupas curtas, justas, no uso de transparência e de decote. Assim, ao mesmo tempo em que celebra o lema feminista "meu corpo, minhas regras" e afronta a ideia tradicionalista de que a mulher precisa se vestir pudicamente, a sua performance visual corrobora uma tendência antiga de erotização e objetificação do corpo da mulher, que é para deleite do olhar masculino. Sendo assim, o modo de vestir da apresentadora não pode ser visto como um dos pontos pelos quais o programa rompe com as performances clássicas de gênero. Além disso, Fernanda ostenta um corpo branco e magro, em conformidade com os padrões de beleza ocidental. Logo, “Amor \& Sexo” é um programa sobre diversidade sendo apresentado por uma mulher cis e heterossexual, característica que ela reconhece explicitamente. A própria Fernanda Lima aborda isso na edição de 26 de janeiro de 2017, passando a voz para que a filósofa feminista Djamila Ribeiro exponha a importância de se ter consciência dos privilégios e, a partir de tal consciência, assumir o papel de dar maior visibilidade às pautas de minorias. Ainda, se expandirmos nossa investigação sobre os modos como os jurados do programa se mostram, percebemos que esses convidados frequentemente usam roupas brilhosas, com mangas exageradas etc, sendo o estilista Dudu Bertholini o mais ousado na apropriação de elementos femininos do vestir. Percebemos que as cores e formas das roupas dos convidados seguem uma conformidade no modo de performar os sexos, com as mulheres frequentemente usando vestidos e saias, modelagens mais ousadas e os convidados masculinos com calças e camisas masculinas ou camisetas. Há, no entanto, duas exceções: o estilista Dudu Bertholini usa frequentemente macacões justos, brilhosos, roupas muito coloridas, brincos e penteados trançados, ousando na apropriação de elementos femininos do vestir; e a roteirista Milly Lacombe frequentemente veste peças que aludem à camisas masculinas de manga curta e camisetas.

Um outro participante nos chama atenção. É o auxiliar de palco chamado de Zentai, denominação que deriva do nome da peça de roupa caracterizada por um macacão de elastano que cobre todo o corpo, inclusive a cabeça, combinando os sentidos de anonimato e fetichismo. Ele se apresenta sempre com um figurino que cobre seu rosto. Andando de patins, Zentai frequentemente mistura formas humanas com animais em seu figurino bastante teatral. 
No episódio de 2 de março de 2017, numa conversa sobre identidade de gênero que ocorreu com uma drag convidada, Fernanda Lima aborda uma categoria pouco discutida no programa, a de agênero. Nenhum dos convidados e ninguém na plateia se autoproclama agênero, exceto Zentai, apontado então como representante dessa categoria. É esta personagem de estilo surreal que integra categorias contrárias de homem/animal, masculino/feminino.

Importante perceber que essa personagem fantasiosa consegue construir, dentro do programa, o espaço de aceitação de diferentes aspectos do gênero como algo subversivo. Essa recriação é vista como sem nexo, como fora das possibilidades de classificação de gênero, mas é Zentai que mais se aproxima da ideia de subversão de gênero.

Em “Amor \& Sexo", há também apontamentos que rompem com a visão tradicional a partir do discurso verbal, como será mostrado a seguir.

\section{ENTRETENIMENTO COM DISCURSO POLITIZADO SOBRE GÊNERO E SEXUALIDADE}

O entretenimento constitui espaço importante para a discussão de direitos sociais, civis e políticos, o "Amor \& Sexo" da TV Globo foi uma produção em que essas discussões foram possíveis. No programa, existem momentos em que há uma tentativa de desestabilizar verdades sociais relacionadas a gênero e sexualidade. A edição do dia 26 de janeiro de 2017 começa com a música "Piranha”, nome de um peixe, de Alípio Martins, que basicamente faz uma brincadeira com o termo empregado para desqualificar uma mulher. Na sequência, Fernanda Lima diz: "Puta, piranha, piriguete, vadia, vagabunda, basta! Chega, deu por hoje. 0 ódio não vai mais controlar o nosso corpo porque juntas somos mais fortes". (LIMA, 2017a) Ainda nesse momento, há um olhar sobre esses termos como sendo negativos, mas na conversa com as cantoras Karol Conka e Gaby Amarantos, os termos são ressignificados.

Fernanda Lima: Se alguém te chamasse de piranha, qual seria sua resposta?

Karol: Eu diria piranha não. Piranhuda. Piranha tombadora

Gaby Amarantos: A escolha é que é importante. Se você quer ser piranha ou se você quer ser a bela, recatada e do lar. 0 importante é ser feliz. Sejamos todas piranhas. Eu sou piranha. Fernanda Lima: 0 problema não está no bela e nem no do lar, mas sim no recatada. Por que a mulher tem que ser recatada?

Gaby Amarantos: Por que é que esse é o modelo correto a ser seguido?. (Amor e Sexo, 2017a) 
Nesse trecho, percebe-se como Karol e Gaby trazem um novo discurso em relação ao termo piranha, elas tentam mostrar que não há problema em ser “vadia”. A psicanalista e escritora Regina Navarro, jurada do programa, diz que a sexualidade feminina sempre incomodou e que esses termos pejorativos surgiram a partir daí. Há também uma referência a uma discussão da época em torno de uma reportagem sobre Marcela Temer, mulher do ex-presidente Michel Temer, segundo a qual a primeira-dama seria “bela, recatada e do lar". Há, no discurso de Amarantos, uma tentativa de subverter esse modelo e essa expectativa em torno da mulher.

No dia 2 de março de 2017, a ideia do programa é festejar a luta pelo orgulho LGBTQIAP+ no Brasil. É no clima de carnaval (um momento do ano em que, no Brasil, permite-se a troca de gêneros, as vestimentas extravagantes e a fantasia) que, em um estado atípico, Regina Navarro traz um discurso que remete a essa possibilidade de não seguir os padrões.

As pessoas sempre tiveram que se enquadrar em modelos, quem não se enquadrasse era discriminado. Então, está mais do que na hora de as pessoas poderem se expressar livremente. (NAVARRO, 2017)

Nessa ideia de liberdade de gênero, a apresentadora apresenta a possibilidade de corpos serem não binários. Fernanda Lima, então, conversa com a atriz Wallace Ruy, perguntando o que seria uma pessoa não binária. Nesse momento, a atriz Wallace Ruy diz:

Não binária é que não é nem 100\% homem, nem 100\% mulher. Eu não passei pelo processo de hormonização, não tenho nenhum processo de cirurgia, mantenho meu nome Wallace Ruy, que é meu nome de origem. Não penso em mudá-lo porque é uma performance. Nada a ver com a sexualidade. Então, assim, se há uma possibilidade de identificação e de poder definir, eu quero ser tudo aquilo que eu puder ser em toda a minha vida. (RUY, 2017)

Outra convidada diz que agênero é uma nomenclatura muito próxima do não binário. “Nem homem nem mulher. Tô fora disso. Me deixa”. (Amor \& Sexo, 2017b) Esses trechos mostram como no programa foram construídos discursos de ruptura com o binarismo de gênero, com o masculino e com o feminino.

O debate exclusivamente sob o ponto de vista biológico se alinha às primeiras discussões sobre gênero surgidas na década de 1960, que usavam o termo como um dado natural que serviria de base para a determinação do gênero. A contraposição a esse entendimento, apresentado no programa e exemplificado nos trechos selecionados, já havia sido formulada por Simone de Beauvoir no final dos anos de $1940 \mathrm{com}$ a famosa 
frase: "não se nasce mulher, torna-se mulher". Com os estudos de Michel Foucault em História da Sexualidade I: a vontade de saber (2009), a compreensão sobre o sexo ganha uma outra perspectiva ao explicá-lo como uma produção do discurso, que governa o modo como falamos e percebemos um momento ou momentos históricos específicos. Para o autor, sexualidade e sexo não seriam verdades em suas essências, mas construções históricas.

A superação da dualidade sexo masculino e feminino aparece nos estudos de Butler (2016), que ressalta a performatividade do gênero. De acordo com a autora, sexo/ gênero precisam ser entendidos a partir de uma perspectiva não natural, mas cultural. Assim, ela aponta como a heterossexualidade obrigatória e reprodutora materializou nos corpos modos de ser masculinos e femininos. No entanto, ela chama atenção para as possibilidades de subversão a esse modelo, as que produzem descontinuidade e dissonâncias em relação ao sexo, gênero e desejo, tais como as apresentadas por "Amor \& Sexo" ao falar sobre pessoas não binárias e agêneras, por exemplo. Os corpos, então, performatizam gêneros a partir de uma estrutura de repetição que contém nela mesma a possibilidade de transgressão.

Para a autora, é importante contestar o status quo e deslocar categorias tais como "homem", "mulher", "macho" e "fêmea”, revelando como elas são discursivamente construídas no interior de uma matriz heterossexual de poder. Ela concorda com Beauvoir que gênero não é algo que somos, mas algo que fazemos. Não é algo que se "deduz" de um corpo. Butler propõe pensar o gênero como algo fluido, socialmente construído, performado, como um "efeito".

Os corpos não se reconhecem mais como homens ou mulheres, mas podem reivindicar as sexualidades que quiserem. O filósofo Paul B. Preciado (2014b) também supera essa visão binária e afirma que o gênero não é apenas performativo, mas resultado de uma tecnologia sofisticada que produz corpos sexuais. 0 estudioso se afilia à perspectiva teórica de Foucault, segundo a qual é preciso recusar o tipo de individualidade que é imposto aos sujeitos. Dessa forma, assim como em Foucault, Preciado (2014b) pensa o sexo, pelo menos a partir do século XVIII, como sendo uma tecnologia biopolítica. "Isto é, como um sistema complexo de estruturas reguladoras que controlam a relação entre os corpos, os instrumentos, as máquinas, os usos e os usuários”. (PRECIADO, 2014b, p. 79) 
Enquanto a maioria dos discursos presentes na sociedade tenta consolidar uma versão do gênero como algo natural, observa-se em “Amor \& Sexo” um caminho que desconstrói essa visão. Preciado (2014a) afirma que os órgãos sexuais não existem em si. Butler (2016) e Preciado (2014a) partem da perspectiva de que até o sexo não é natural, mas uma construção. Mostram como o mundo heteronormativo impôs esses dados como verdades universais e naturais e defendem que, apesar de serem feitos sob essas perspectivas, tanto os sexos quanto os gêneros podem ser construídos de maneiras diferentes e subversivas.

Preciado apresenta, então, os conceitos de contrassexualidade e sexopolítica como recursos que rompem com a ordem de opressão e sujeição dos corpos. Seguindo os passos de Preciado, cada vez mais vemos análises de performances não normativas de gênero como as abordadas pelo programa “Amor e Sexo”. A ideia de um manifesto contrassexual, vinda do pensador transgênero espanhol, parte da concordância com Butler de que o gênero deve ser definido:

não como uma essência ou uma verdade psicológica, mas como um corpo performativo e uma prática discursiva através da qual o sujeito adquire inteligibilidade social e reconhecimento político. (PRECIADO, 2014c, p. 95)

Para Preciado (2014a), as práticas contrassexuais devem ser compreendidas como tecnologias de resistência e como forma de contradisciplina sexual. A sexopolítica, por sua vez, seria uma forma de ação biopolítica que passa a ser dominante no capitalismo contemporâneo, especialmente a partir de 1950, com a ruptura do regime disciplinar do sexo. A sexopolítica “dobra” a própria noção de biopolítica foucaultiana, compreendendo os corpos e as identidades dos anormais como potências políticas, como o que existe para romper os padrões, diferente da biopolítica, que está ligada a esses padrões. (ROSA, 2016) Trata de corpos que efetuam a profanação da monotonia das conexões binárias e de uma suposta correspondência entre sexo, gênero e orientação sexual. (PRECIADO, 2014b)

Também no programa do dia 2 de março de 2017, ao abordar o bullying, Fernanda Lima ressalta possibilidades de se romper com o padrão heteronormativo e ainda trata de questão de direitos LGBTQIAP+.

É uma questão de poder e de controle. Não colabore com o seu agressor. Não se deixem controlar. Se você sofreu agressão física ou sexual, procure o núcleo de combate à discriminação da defensoria pública ou conselho tutelar. Tem também as ongs LGBTs e disque 100 pro 
Departamento Nacional de Direitos Humanos. O Marlon Parente de Recife é diretor de um documentário chamado "Bichas". Marlon, o que te levou a produzir o filme?. (LIMA, 2017b)

\section{Marlon Parente responde:}

A palavra bicha não é estranha para nenhum menino, para nenhum homem gay, homossexual. A gente escuta bicha desde pequeno e isso nunca, nunca, nunca é bom. Em uma das vezes que eu escutei bicha, o cara apontou a arma para minha cabeça e disse que ia me matar porque eu era bicha. Para ajudar a lidar com o meu trauma, eu peguei a palavra que ele usou. Uma vez que eu pego a palavra para mim: “Ah, você é bicha!”, “Ai, muito obrigada, não poderia dormir hoje sem saber que eu sou bicha, obrigada". Acabou a agressão. Você vai ter que arrumar outra palavra porque essa não me machuca mais. Sou bicha sim com muito orgulho. (PARENTE, 2017)

Na sequência, a cantora Lynn da Quebrada canta:

Se liga, macho, senta e observa a tua destruição. Eu sou uma bicha, preta, louca, favelada e quando eu passar ninguém mais vai dar risada. Se tu for esperto, pode logo perceber que eu já não tô pra brincadeira, eu vou botar é pra fuder.... Bicha estranha, ensandecida, arrombada, pervertida, elas tão pra fechar causa, elas são muita lacração. (QUEBRADA, 2017)

Nesses momentos, percebemos uma reapropriação do termo "bicha". Em nome da inversão e ressignificação de valores implicados na própria linguagem cotidiana, uma antiga denominação pejorativa se transforma. Há uma inversão de lógicas tradicionais. A ideia é desafiar, questionar publicamente conceitos que hierarquizam os sujeitos e conferir significados positivos a uma qualificação pejorativa.

Duarte (2016), em um estudo sobre a Marcha das Vadias, escreve:

Assim, quando os/as manifestantes gritam publicamente "somos vadias!", o que se instaura não é um clamor por tolerância, aceitação e reconhecimento do direito à diferença, mas sim um gesto de autoafirmação que desnaturaliza e torna risível o preconceito entranhado nos processos de identificação, triagem e valoração cotidiana dos sujeitos respeitáveis e de seus negativos abjetos. (DUARTE, 2016, p. 44)

E é exatamente isso que o programa propõe quando subverte os termos "bicha, piranha”. É fazer com que esses termos percam o sentido de desqualificação de uma pessoa e, assim, apresentem novas possibilidades de se entender gênero e sexualidade.

Além de uma ressignificação de termos, há, em “Amor \& Sexo”, em 23 de outubro de 2018, uma discussão sobre família, em que novos modelos são apresentados. Fernanda Lima diz: 
Por que a família brasileira ainda é retratada como nos tempos da vovozinha? Quem é afinal de contas a família brasileira? "Amor \& Sexo" declara: somos muitos, somos brancos, negros, índios, 2, 3, 4, 6, 10, 1. Somos pai e mãe, mãe e mãe, pai e pai, mãe solo, pai solo, filho dele, filho dela, nossos filhos, somos incluídos, excluídos, ligados pelo nosso sangue, por afeto, respeito. E amor. Compartilhamos lar, mesa e dor. (LIMA, 2018a)

Interagindo com um especialista, o programa conceitua diversas modalidades de famílias. Entre elas: família homoafetiva, unipessoal, monoparental. A ideia é deixar claro que não existe somente a família formada por homem e mulher, como propõe a discussão do Estatuto da Família, projeto de lei apresentado na Câmara Federal que propõe regras jurídicas para definir quais grupos podem ser considerados uma família perante a lei. Há uma desconstrução do modelo de família e a proposição de novas possibilidades.

No programa do dia 6 de novembro de 2018, duas semanas após a eleição de Jair Bolsonaro como presidente do Brasil, a apresentadora afirma:

Chamam de louca a mulher que desafia as regras e não se conforma. Chamam de louca a mulher cheia de erotismo, vida e tesão. Chamam de louca a mulher que resiste. Chamam de louca a mulher que diz sim e que diz não. Não importa o que façamos, nos chamam de louca. Se levamos a fama, vamos sim deitar na cama, vamos sabotar as engrenagens deste sistema de opressão. Vamos sabotar as engrenagens desse sistema homofóbico, racista, patriarcal, machista e misógino. Vamos jogar na fogueira as camisas de força da submissão, da tirania e da repressão. Vamos libertar todas nós! E todos vocês! Nossa luta está apenas começando, prepare-se porque esta revolução não tem volta. Vamos sabotar tudo isso? [convidou a apresentadora]. (LIMA, 2018b)

Há, no programa, mais uma vez um discurso disruptivo em relação ao vigente, especialmente se considerarmos o candidato eleito e o discurso de ódio e de normatização de identidades de gênero proposta por ele. Quando fala em sabotar as engrenagens do sistema homofóbico, racista, patriarcal, machista e misógino, Fernanda Lima convoca a audiência a combater a heterossexualidade normativa e o enclausuramento identitário.

“Amor \& Sexo" atuou a partir de uma perspectiva em que o gênero não era visto apenas como natural. Apesar dos esforços em construir essa ideia, a concepção de sexo é abordada sob um ponto de vista naturalizado. Isso é possível perceber na edição de 2 de março de 2017. Nela, Fernanda Lima diz:

Sexo biológico é aquele no qual você nasce. A identidade de gênero é cultural. 0 ser humano pode não se identificar com o sexo biológico. Orientação sexual é a inclinação do seu desejo, ou seja, por quem você se sente atraído amorosa ou sexualmente. Isso não é de hoje. Isso 
não é coisa de moda. Isso não é papo do "Amor \& Sexo". Essa diversidade sempre existiu ao longo de toda a nossa história. A diferença é que hoje as pessoas não precisam viver escondidas ou frustradas por não poderem ser como se sentem de verdade. 0 mundo vem mudando, ouvindo outras vozes, afinando os pensamentos e multiplicando a possibilidade de viver em plenitude. Ainda bem, não é?. (LIMA, 2017b)

No início do discurso, a apresentadora fala sobre sexo como um dado biológico, natural e imutável. Fernanda Lima mostra didaticamente que o sexo biológico é aquele com o qual as pessoas nascem, naturalizando o binarismo, e prossegue dizendo que a identidade de gênero é cultural. Podemos interrogar essa noção de sexo biológico junto a Butler (2016), que questiona se a dualidade do sexo é produzida discursivamente por vários textos científicos a serviço de interesses políticos e sociais. Para a autora,

se o caráter imutável do sexo é contestável, talvez o próprio construto chamado "sexo" seja tão culturalmente construído quanto o gênero; a rigor, talvez o sexo sempre tenha sido o gênero, de tal forma que a distinção entre sexo e gênero revela-se absolutamente nula [...] Resulta daí que o gênero não está para a cultura como o sexo para a natureza; ele também é o meio discursivo/cultural pelo qual a "natureza sexuada" ou "um sexo natural" é produzido e estabelecido como "pré-discursivo", anterior à cultura, uma superfície politicamente neutra sobre a qual age a cultura. (BUTLER, 2016, p. 27)

A noção de sexo biológico que a produção televisiva propaga reverbera o discurso veiculado pelas organizações LGBTQIAP+ em seus materiais informativos sobre o modo como o discurso de gênero pode ser abordado. (REIS, 2018) Um olhar sobre esse material, em conjunto com publicações governamentais que também visam esclarecer sobre o assunto (SECRETARIA DA JUSTIÇA E DA CIDADANIA, 2018; SECRETARIA DE POLÍTICAS PARA AS MULHERES, 2014), mostra que o discurso do programa não difere em sua essência daquele presente nos movimentos sociais.

Há a defesa do sexo biológico como associação ligada às informações que depreendemos de um corpo físico. A cartilha sobre diversidade sexual do Governo de São Paulo (SECRETARIA DA JUSTIÇA E DA CIDADANIA, 2018), por exemplo, e o "Manual de comunicação LGBTI+" (REIS, 2018) incluem uma gama de informações que poderiam ser responsáveis por se classificar um corpo como "macho" ou "fêmea", ao definir o sexo biológico como "características biológicas que a pessoa tem ao nascer. Podem incluir cromossomos, genitália, composição hormonal, entre outros". (REIS, 2018, p. 18) Tal definição coaduna com o material educativo do Governo de São Paulo, no qual o sexo biológico é um "conjunto de informações cromossômicas, órgãos genitais, capacidades 
reprodutivas e características fisiológicas secundárias que distinguem machos e fêmeas”. (SECRETARIA DA JUSTIÇA E DA CIDADANIA, 2018, p. 14)

Por isso, o discurso do programa reproduz o discurso propagado socialmente, nos textos governamentais apresentados anteriormente, para a educação das pessoas. É também interessante destacar que em alguns momentos a própria noção da cartilha e do manual sobre as características que compõe o sexo biológico muda, reduzindo o sexo biológico apenas ao caráter anatômico. “Assim, homens e mulheres são produtos da realidade social e não decorrência direta da anatomia de seus corpos” (SECRETARIA DA JUSTIÇA E DA CIDADANIA, 2018, p. 15, grifo nosso).

No geral, os textos educativos e aqueles produzidos pelos próprios movimentos LGBTQIAP+ apresentam a mesma concepção divulgada no programa. "O fato de uma pessoa nascer com um pênis não significa que ela irá automaticamente gostar de futebol e 'falar grosso'. Da mesma forma, nascer com uma vagina não faz com que a pessoa seja emotiva e vaidosa”. (SECRETARIA DA JUSTIÇA E DA CIDADANIA, 2018, p. 15, grifo nosso) Percebemos, assim, que a tomada do sexo biológico por sua anatomia é ainda uma questão presente no discurso social, e a confusão se extravasa por materiais educativos, simplificando a concepção de sexo biológico para informar ao público as diferenças entre sexo biológico e identidade de gênero.

Também na edição do dia 2 de março de 2017, há um desfile de drags e uma competição, da qual participa uma drag misteriosa, maneira pela qual é anunciada. No final, depois de cumprimentar uma a uma, Fernanda Lima beija, sem falar nada, a drag cuja identidade não tinha sido revelada. Tratava-se de Rodrigo Hilbert, marido da apresentadora. Ela diz: “Está tão feminino. O Rodrigo é cheio de atributos femininos. Que ele cozinha, todo mundo sabe, mas [ele] também lava, passa, cuida quase que integralmente das crianças nesse período que eu tô vivendo aqui no 'Amor \& Sexo' e ainda faz tricô. Eu amo esse homem”. (LIMA, 2017b)

Nesse trecho, é possível identificar como a apresentadora volta para uma concepção "natural" dos papéis de homens e mulheres na sociedade. Ela reforça o modelo homem/ mulher, macho/fêmea, quando poderia avançar em um movimento de desconstrução dessa perspectiva, como visto em outros momentos do programa.

Ainda nesta edição, a apresentadora diz: 
Só para a gente ter uma ideia, a Comissão de Direitos Humanos de Nova lorque decidiu por oficializar essa multiplicidade. Então, no lugar de ter somente duas ou três identidades oficiais, a comissão, com o propósito de garantir direitos a todos, ampliou a lista para nada menos que 31 nomenclaturas de gênero. (LIMA, 2017b)

Apesar de ressaltar a multiplicidade de gêneros quando se refere às contas feitas pela Comissão de Direitos Humanos de Nova lorque, nas explicações sobre a identidade de gênero, em um quadro que a produção chama de "Telecurso do Gênero", a questão do sexo biológico reduzido a anatomia volta a ser empregada.

Então, a título exclusivamente didático para aprender, entender, eu apresento aqui o telecurso de gênero e é claro que em 50 minutos é sempre muito, mas esse panorama pode ajudar a entender alguns gêneros. [...] Homem cisgênero: nasceu com o pênis e se identifica como homem. [...] Mulher cisgênera. nasceu com vagina e se identifica como mulher. [...] Homem trans: nasceu com vagina e se identifica como homem. [...] Mulher trans: nasceu com pênis e se identifica como mulher. [...] Até aqui a gente falou de binarismo, ou seja, quem se identifica com as identidades femininas ou masculinas, mas existem também aqueles que transitam entre um e outro que são não binários ou fluidos. (LIMA, 2017b)

Ela inicia pela adjetivação de cis, que busca denotar a concordância entre o sexo biológico e o sexo pelo qual a pessoa se identifica. Mas Fernanda Lima ainda expõe, como exclusivamente significante do sexo biológico, as características anatômicas do órgão sexual e a concordância desse órgão com o gênero adotado pelo indivíduo no âmbito social.

O programa expõe sua ambiguidade no modo de tratar a questão quando essa discussão culmina com o incômodo de alguns convidados do programa sobre o fato de as pessoas quererem saber o que eles têm, em suas próprias palavras, “entre as pernas”. Cai-se, então, num discurso da liberdade de cada um poder se identificar com o gênero que quiser. Mas, a partir do momento que a concepção matriz de sexo é binária e dada como imponderável, há uma ambiguidade em expor o tema como algo maleável socialmente e o modo naturalizado de se tratar classificações biológicas. Nesse episódio, tal discussão se encerra com a conclusão de cada um poder escolher o que se quer ser, expondo uma versão da identidade como supermercado de estilos, em que a cada dia o indivíduo poderia escolher de modo autônomo ou independente com o que se identificar em relação ao gênero. Tal noção vem da moda e do consumo, o pesquisador de moda, o inglês Ted Polhemus (1996), cunha o termo "supermercado de estilos" para descrever a multiplicidade de combinações permitidas entre a variedade de grupos culturais e 
identitários, que se tornam grandemente presentes desde os anos 1950, e a ascensão da cultura jovem. O mundo do consumo busca, então, melhor atender o desejo de consumo desses grandes grupos, então essa liberdade de escolha é colocada como a chave para que um consumo lúdico, próprio dessa cultura jovem, alavanque as possibilidades de compra de modo a não ser excludente com seus consumidores.

O imperativo das escolhas dos modos de parecer dos indivíduos foi abordado por Bauman, que descreve como a cultura consumista é assentada sobre a impressão da autonomia das escolhas (uma vez que as opções são dadas de saída, tal liberdade pode ser questionada) e seu imperativo: “O que de fato importa é que quem está no comando agora é você. E no comando você deve estar: a escolha pode ser sua, mas lembre-se de que fazer uma escolha é obrigatório". (BAUMAN, 2008, p. 110)

Por isso, apesar de apaziguar as discordâncias entre as constrições que são vistas como naturalizadas e aquelas tidas como culturais, o desaguar conclusivo da questão da identidade de gênero numa liberdade radical do sujeito é problemático por continuar a situar a pretensa escolha do sujeito em categorias construídas sobre uma matriz heterossexual.

\section{CONSIDERAÇÕES FINAIS}

“Amor \& Sexo” foi exibido até 2018, quando foi cancelado pela Rede Globo por causa dos baixos índices de audiência. Na época, o boicote ao programa de uma parcela mais conservadora da sociedade também interferiu na decisão da emissora que, nos anos anteriores, não havia enfrentado um desempenho como no ano das eleições para presidência. Com a polarização política e o avanço de pautas contrárias aos direitos de mulheres e população LGBTQIAP+, o programa se tornou alvo de grupos apoiadores de Jair Bolsonaro e contrários aos direitos civis, sociais e políticos dos grupos sociais priorizados na produção televisiva comandada por Fernanda Lima.

Ela, depois da exibição do episódio do dia 6 de novembro de 2018, foi atacada nas redes sociais por grupos que apoiavam a vitória de Jair Bolsonaro. (QUERINO, 2018) O cantor sertanejo Eduardo Costa chegou a dizer:

Mais de 60 milhões de brasileiros e brasileiras votaram no Bolsonaro e agora essa imbecil com esse discurso de esquerdista!!! Ela pode ter certeza de uma coisa, a mamata vai acabar, a corda sempre arrebenta pro lado mais fraco e o lado mais fraco hoje é o que ela está. Será 
que essa senhora só faz programa pra maconheiro, pra esquerdista derrotado e pra esses projetos de artistas assim como ela?. (SOUSA, 2018)

A apresentadora chegou a bloquear comentários em suas redes. Fica claro, a partir do que foi apresentado neste artigo, que "Amor \& Sexo" desagradava grupos direitistas por avançar na perspectiva de identidade de gênero no campo do entretenimento, a partir das rupturas e fracionamentos com o modelo hegemônico. Ao discutir em torno de padrões sexuais e de gênero, "Amor \& Sexo" explorava modelos que desterritorializavam a heterossexualidade e toda cultura a ela associada. Portanto, quando o programa decide abordar gênero e sexualidade a partir das pautas políticas de movimentos sociais feministas e LGBTQIAP+, sabia-se a resistência que precisaria ser enfrentada, especialmente em um momento político como o vivido em 2018.

Observamos que a produção televisiva adotava muitas vezes um tom lúdico e educacional, abordando a possibilidade de se pensar a diversidade de gênero segundo parâmetros colocados pelos próprios grupos LGBTQIAP+. Entendemos que a abordagem de pautas políticas identitárias por meios massivos de televisão torna esses programas um local de disputa de discursos por segmentos políticos, que hoje encontram-se tão polarizados.

Tanto o discurso verbal da apresentadora como o discurso imagético do programa puderam ser abordados, aqui, como meio de entendimento do modo como a produção televisiva exibia a pluralidade e as possibilidades de rupturas do binarismo de gênero. Nesse ponto, o programa mostra grande avanço. Em “Amor \& Sexo", a noção de identidade de gênero é anunciada conforme defende boa parte dos movimentos sociais feministas e LGBTQIAP+: "A identidade de gênero é cultura" (LIMA, 2017b), não é natural. Em vez disso, é a própria nomeação de um corpo, sua designação como macho ou como fêmea, como masculino ou feminino, que "faz" esse corpo.

Mas também pudemos observar a existência de um discurso reducionista sobre o sexo biológico, que espelha a própria confusão ainda existente no discurso de conscientização sobre esse tema em nossa sociedade. Nesse sentido, os estudos de Butler e Preciado puderam apontar possibilidades de novos horizontes para a discussão desse tópico que o programa não chega a debater.

Por meio da exibição de formas e fórmulas do entretenimento, como apresentações musicais e jogos, “Amor \& Sexo” buscou abordar temas políticos de modo lúdico. Tornou-se, 
então, um espaço de exibição de embates fora das telas e apontou o entretenimento como local de resistência e de expansão de ideias de direitos políticos e identitários.

Este trabalho teve como pretensão entender quais as estratégias discursivas utilizadas pelo programa. Dessa forma, o artigo abre caminho para investigações que contribuam em compreender a escolha de emissoras de televisão em tratar de questões sobre identidade de gênero em sua programação.

\section{REFERÊNCIAS}

Amor \& Sexo. Rio de Janeiro: Rede Globo, 26 jan. 2017. Programa de TV.

BAUMAN, Zygmunt. Vida para consumo: a transformação das pessoas em mercadoria. Rio de Janeiro: Zahar Editora, 2008.

BUTLER, Judith. Revisiting bodies and pleasures: Foucault and the politics of sexual normalization.

Theory, Culture and Society, Londres, v. 16, n. 2, p. 11-20, 1999.

BUTLER, Judith. Problemas de Gênero: feminismo e subversão da identidade. 10. ed. Rio de Janeiro: Civilização Brasileira, 2016.

CÉSAR, Maria Rita de Assis. A crítica da noção de identidade e atualizações contemporâneas da estética da existência: feminismo(s), movimentos LGBT e política queer. In: RESENDE, Haroldo de (org.). Michel Foucault: política - pensamento e ação. Belo Horizonte: Autêntica Editora, 2016. p. 137-146.

DUARTE, André. Foucault e os coletivos políticos: novas formas de vida para além do sujeito identitário de direitos. In: RESENDE, Haroldo de (org.). Michel Foucault: política - pensamento e ação. Belo Horizonte: Autêntica Editora, 2016. p. 35-49.

FOUCAULT, Michel. História da Sexualidade I: a vontade de saber. 19. ed. Rio de Janeiro: Graal, 2009. LAZZARATO, Maurizio. Signos, Máquinas, Subjetividades. São Paulo: Sesc, 2014.

LIMA, Fernanda. In: REDE GLOBO. Amor \& Sexo [Mulher]. Rio de Janeiro: Rede Globo, 26 jan. 2017 a. Programa de TV.

LIMA, Fernanda. In: REDE GLOBO. Amor \& Sexo [Orgulho LGBT]. Rio de Janeiro: Rede Globo, 2 mar. 2017b. Programa de TV.

LIMA, Fernanda. In: REDE GLOBO. Amor \& Sexo [Família]. Rio de Janeiro: Rede Globo, 23 out. 2018a. Programa de TV.

LIMA, Fernanda. In: REDE GLOBO. Amor \& Sexo [Estereótipos femininos e machismo]. Rio de Janeiro: Rede Globo, 6 nov. 2018b. Programa de TV. 
NAVARRO, Regina [entrevista]. In: Amor \& Sexo. Apresentado por Fernanda Lima. 45 min, col, 2017. Disponível em: globoplay.com. Acesso em: 10 jan. 2020.

PARENTE, Marlon [entrevista]. In: Amor \& Sexo. Apresentado por Fernanda Lima. 45 min, col, 2017. Disponível em: globoplay.com. Acesso em: 10 jan. 2020.

POLHEMUS, Ted. Style Surfing: what to wear in the 3rd millennium. Londres: Thames and Hudson, 1996.

PRECIADO, Paul Beatriz. Manifesto Contrassexual. São Paulo: n-1 edições, 2014a.

PRECIADO, Beatriz. Historia de la tecnossexualidad. In: PRECIADO, Beatriz. Testo Yonqui: sexo, drogas y biopolítica. Buenos Aires: Paidós, 2014b. p. 63-73.

PRECIADO, Beatriz. Tecnogénero. In: PRECIADO, Beatriz. Testo Yonqui: sexo, drogas y biopolítica. Buenos Aires: Paidós, 2014c. p. 89-109.

QUEBRADA, Lynn da [entrevista]. In: Amor \& Sexo. Apresentado por Fernanda Lima. 45 min, col, 2017. Disponível em: globoplay.com. Acesso em: 10 jan. 2020.

QUERINO, Rangel. Após polêmica e baixa audiência, Globo cancela "Amor \& Sexo". Uol - Observatório G, São Paulo, 19 nov. 2018. Cultura. Disponível em: https://observatoriog.bol.uol.com.br/ noticias/2018/11/apos-polemica-e-baixa-audiencia-globo-cancela-amor-sexo. Acesso em: 27 abr. 2020. REIS, Toni (org.). Manual de comunicação LGBTI+. Curitiba: Aliança Nacional LGBTI/Gay Latino, 2018. Disponível em: https://unaids.org.br/wp-content/uploads/2018/05/manual-comunicacao-LGBTI.pdf. Acesso em: 26 abr. 2020.

RIBEIRO, Irineu Ramos. A TV no armário: a identidade gay nos programas e telejornais brasileiros. São Paulo: GLS, 2010.

ROSA, Susel Oliveira da. Entre a biopolítica e a sexopolítica. In: RESENDE, Haroldo de (org.). Michel Foucault: política - pensamento e ação. Belo Horizonte: Autêntica Editora, 2016. p. 213-222.

RUY, Wallace [entrevista]. In: Amor \& Sexo. Apresentado por Fernanda Lima. 45 min, col, 2017. Disponível em: globoplay.com. Acesso em: 10 jan. 2020.

SALIH, Sara. Judith Butler e a Teoria Queer. Belo Horizonte: Autêntica, 2015.

SECRETARIA DA JUSTIÇA E DA CIDADANIA. Diversidade sexual e cidadania LGBT. Coordenação de Políticas para a Diversidade Sexual. 3. ed. São Paulo: Secretaria da Justiça e da Cidadania, 2018. SECRETARIA DE POLÍTICAS PARA AS MULHERES. Direitos iguais nas diferenças: cartilha da diversidade de gênero. Rio Grande do Sul: Secretaria de Políticas para as mulheres, 2014. 
SOUSA, Silvana. Eduardo Costa ofende Fernanda Lima e Hilbert sai em defesa da esposa. Correio Brasiliense, Brasília, 9 nov. 2018. Diversão e Arte. Disponível em: https://www.correiobraziliense.com. br/app/noticia/diversao-e-arte/2018/11/09/interna_diversao_arte,718504/eduardo-costa-ofendefernanda-lima-e-hilbert-sai-em-defesa-da-esposa.shtml. Acesso em: 27 abr. 2020.

Artigo recebido em: 10 de março de 2019.

Artigo aceito em: 6 de maio de 2020 . 